\title{
Judging a book by its cover: descriptive survey of patients' preferences for doctors' appearance and mode of address
}

\author{
Marianne M Lill, Tim J Wilkinson
}

Christchurch

School of Medicine and Health

Sciences, University

of Otago,

New Zealand

Marianne M Lill

medical student

Tim J Wilkinson

associate professor

Correspondence to:

Dr Tim Wilkinson,

Princess Margaret

Hospital, PO Box 800

Christchurch,

New Zealand

tim.wilkinson@

hmeds.ac.nz

\begin{abstract}
Objective To document patients' preferred dress styles of their doctors and modes of address.

Design Descriptive survey.

Setting Inpatients and outpatients at a tertiary level hospital, New Zealand.

Participants 202 inpatients and 249 outpatients, mean age 55.9 (SD 19.3) years.

Main outcome measures Ranking of patients' opinions of photographs showing doctors wearing different dress styles. A five point Likert scale was used to measure patient comfort with particular items of appearance.

Results Patients preferred doctors to wear semiformal attire, but the addition of a smiling face was even better. The next most preferred styles were semiformal without a smile, followed by white coat, formal suit, jeans, and casual dress. Patients were more comfortable with conservative items of clothing, such as long sleeves, covered shoes, and dress trousers or skirts than with less conservative items such as facial piercing, short tops, and earrings on men. Many less conservative items such as jeans were still acceptable to most patients. Most patients preferred to be called by their first name, to be introduced to a doctor by full name and title, and to see the doctor's name badge worn at the breast pocket. Older patients had more conservative preferences.

Conclusions Patients prefer doctors to wear semiformal dress and are most comfortable with conservative items; many less conservative items were, however, acceptable. A smile made a big difference.
\end{abstract}

\section{Introduction}

First impressions can make a difference. How a doctor dresses may be important in determining the success of the patient-doctor relationship. ${ }^{1}$

Doctors' attire has been moulded by tradition and fashion over centuries. The past decades have seen major changes to the medical workforce and to societal expectations that have led to changes in doctors' choice of dress. One change is the increased proportion of female doctors entering the profession with no traditionally defined "dress code." Another is the move away from medical paternalism, resulting in fewer doctors choosing the traditional white coat. Overall, doctors' dress styles have become less formal than in previous decades.

Most previous studies have focused on white coats. Two Australian studies showed that $36-59 \%$ of patients thought that junior doctors should wear white coats. ${ }^{2}{ }^{3}$ Reasons given included professionalism, identification, and hygiene, yet white coats may be a source of, rather than a barrier to, cross infection. ${ }^{4}$

British and American studies carried out up to the late 1990s showed that patients were more comfortable with traditional styles of appearance, such as white coats, formal suits, short hair, shirts, and ties. ${ }^{56}$ Casual items such as sandals, sports shoes, and jeans evoked negative responses. Other factors, such as neatness or facial expression, were also considered important and had the potential to over-ride the effects of attire. ${ }^{78}$

Reported preferences may be contradicted when patients see actual examples of different dress styles. ${ }^{9}$ Two studies involved dress styles being alternated in doctors to compare measurement of patient satisfaction, and found that dress did not correlate with estimates of a clinician's courteousness, concern, or professionalism. ${ }^{90}$

Just as fashion changes so may opinions. More contemporary views are needed. Furthermore, few studies have looked at clothing options other than white coats. Preferences may be determined by the familiar, so that if a doctor wears a white coat this may become acceptable to the patient. Similarly, style of dress may depend on the work culture of an institution. Many doctors adapt their styles to fit in with colleagues' expectations, whereas some attempt to stand out deliberately. Doctors may also dress in a way that they feel is acceptable to their patients, and it is likely that patients dress to please their doctors.

These complex interplays can result in novice doctors becoming unclear about best practice, and many of our junior colleagues have asked for current information about what dress styles are acceptable to patients. We documented the preferences of a range of patients within one hospital, with the aim of informing doctors' practice.

\section{Methods}

We invited adult inpatients and outpatients at Christchurch Hospital, New Zealand to take part in the study. Outpatients attending clinics that covered a range of medical and surgical specialties were approached consecutively in the waiting room over one week in December 2003. Inpatients from a wide range of wards were surveyed sequentially over another week. Inpatients were excluded if the nursing staff deemed them too unwell or if they were absent from their bed for an extended period on the specific day.

Our survey comprised two parts. For the first part we presented patients with two sets of six photographs-one set of a young male doctor and the other of a young female doctor (see bmj.com). Each photograph depicted a different dress style. These styles were casual, jeans, semiformal, white coat, and formal suit. The sixth photograph showed a semiformal style with the doctor smiling. The casual photographs showed the male doctor wearing khaki trousers and a polo shirt and the female doctor wearing a sleeveless top, sandals, and short skirt. Other photographs showed both doctors wearing jeans, but with the male doctor wearing a short sleeved shirt with a collar and the female doctor a long sleeved knitted top. The semiformal photographs showed the male doctor wearing dark trousers with a long sleeved shirt and tie and the female doctor a blouse with a dark col- 
Professional matters

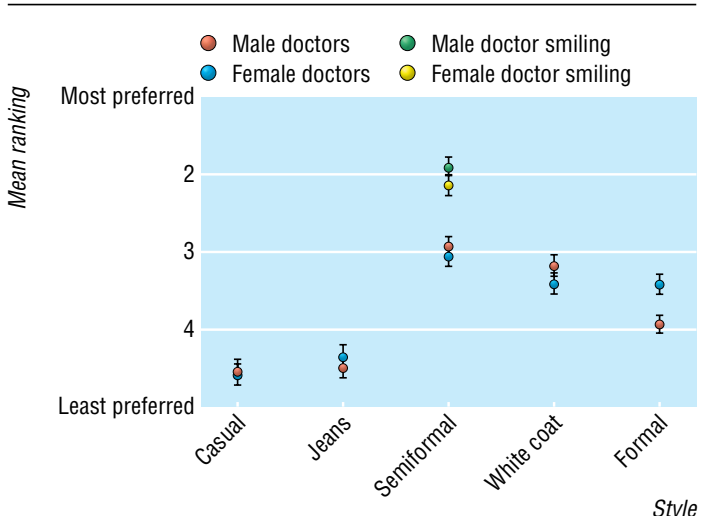

Fig 1 Patients' mean rankings (95\% Cls) for doctors' dress

oured skirt or trousers. The white coat photographs had both doctors wearing dark trousers. A fifth style had male and female doctors wearing dark suits. For all photographs the stance, position of the stethoscope, and hairstyle were kept constant. The photographs were presented to patients in random order.

Patients were asked to rank each set in order from their most preferred doctor (ranked 1) to their least preferred (ranked 6). They were asked to choose their four most preferred doctors from the complete set of 12 photographs (no order or sex restriction required).

In the second part of the survey the patients were asked to complete a written questionnaire, which included requests for personal information and questions on the degree of comfort each respondent felt with doctors wearing specified items of clothing. Responses were graded according to a five point Likert scale, ranging from "very uncomfortable" to "very comfortable." In addition participants were asked where identification tags should be worn, what name they liked to be referred to by their doctor (first name or title and surname), and how they liked doctors to introduce themselves. We provided four options for a doctor's introduction: first name only, first and last name, title and first and last name, and title and surname. Options for the location of an identification tag were at the waist, breast pocket, or anywhere as long as a name badge was worn.

We calculated mean ranks for the photograph sets and compared these using Student's $t$ tests. Mean scores were calculated for each Likert scale question. We used analysis of variance or Student's $t$ test to compare respondent's ages according to preferences and to compare rankings or scores according to age groups. A Bonferroni correction was made to adjust for multiple comparisons such that differences were regarded as significant if the $\mathrm{P}$ value was less than 0.0012 . We calculated a projected sample size of 450 to provide 0.80 power at $\alpha=0.05$ to obtain descriptive statistics with a $4 \%$ margin of error.

\section{Results}

The sample population comprised 606 patient; 155 declined or were unavailable. We recruited 249 outpatients and 202 inpatients, comprising 214 men and 232 women (five did not provide their sex) with a mean age of 55.9 years (SD 19.3 years). Six people did not
Table 1 Comparison of mean rankings of doctors' dress styles

\begin{tabular}{lllllr} 
Style $\mathbf{A}$ & $\begin{array}{c}\text { Mean ranking } \\
(\mathbf{9 5 \%} \mathbf{~ C l})\end{array}$ & \multicolumn{1}{c}{ Style $\mathbf{B}$} & $\begin{array}{c}\text { Mean ranking } \\
\mathbf{( 9 5 \%} \mathbf{~ C I})\end{array}$ & P value $^{*}$ \\
\hline Male doctors & & & & \\
\hline Semiformal plus smile & $1.90(1.78$ to 2.02$)$ & Semiformal, no smile & $2.92(2.81$ to 3.03$)$ & $<0.001$ \\
\hline Semiformal & $2.92(2.81$ to 3.03$)$ & White coat & $3.18(3.04$ to 3.32$)$ & 0.036 \\
\hline White coat & $3.18(3.04$ to 3.32$)$ & Formal suit & $3.94(3.82$ to 4.06$)$ & $<0.001$ \\
\hline Formal suit & $3.94(3.82$ to 4.06$)$ & Jeans & $4.50(4.36$ to 4.64$)$ & $<0.001$ \\
\hline Jeans & $4.50(4.36$ to 4.64$)$ & Casual & $4.56(4.40$ to 4.72$)$ & 0.43 \\
\hline Female doctors & & & & & \\
\hline Semiformal plus smile & $2.14(2.01$ to 2.27$)$ & Semiformal, no smile & $3.07(2.95$ to 3.15$)$ & $<0.001$ \\
\hline Semiformal & $3.07(2.95$ to 3.19$)$ & White coat & $3.41(3.27$ to 3.55$)$ & $<0.01$ \\
\hline White coat & $3.41(3.27$ to 3.55$)$ & Formal suit & $3.42(3.29$ to 3.55$)$ & 0.92 \\
\hline Formal suit & $3.42(3.29$ to 3.55$)$ & Jeans & $4.37(4.20$ to 4.54$)$ & $<0.001$ \\
\hline Jeans & $4.37(4.20$ to 4.54$)$ & Casual & $4.59(4.46$ to 4.72$)$ & 0.02 \\
\hline
\end{tabular}

*Style A compared with style B.

provide their age. In total, 127 people were aged less than 45 (28\%), 144 were $45-65$ (32\%), and 174 were more than $65(39 \%)$.

Figure 1 shows the distributions of mean ranks for each of the clothing styles, including the results for the photographs with doctors smiling. Patients ranked the semiformal style the best, especially when accompanied by a doctor smiling.

Table 1 shows the mean rankings and significance of the differences for paired dress styles. Each style is compared with the next most popular style overall. Table 2 shows the proportions of each style chosen among patients' top four.

A patient's age was significantly associated with the photograph rankings for some clothing styles. The smiling photograph was excluded from this analysis. Older people gave more negative rankings for the male doctor in semiformal style (mean ranking 1.9 for people under 45, 1.9 for people aged 45-65, and 2.5 for people older than $65 ; \mathrm{P}<0.0001$ ). We found no effect of patient's age for the female doctor in semiformal style. Older patients gave more positive rankings for male doctors wearing white coats (mean ranking 2.9 for people under 45, 2.5 for people aged 45-65, and 2.3 for people older than 65; $\mathrm{P}<0.0001$ ) and for female doctors (mean ranking of 3.2 for people under 45, 2.7 for people aged 45-65, and 2.4 for people aged more than $65 ; \mathrm{P}<0.0001)$.

Figures 2 and 3 show the relative rankings of the selected dress styles for female and male doctors, respectively. Age was significantly associated with responses to specific items of clothing. Items worn by female doctors that were significantly $(\mathrm{P}<0.001)$ less acceptable to older patients were (in order starting with the least acceptable by mean ranking) facial piercings, short tops, brightly dyed hair, training shoes, sandals, loose hair, skirts above the knee, long earrings, several rings, and sleeveless tops. Items worn by male doctors that were significantly $(\mathrm{P}<0.001)$ less acceptable to

Table 2 Proportions of each style chosen in patients' top four

\begin{tabular}{lcc} 
Dress style & Male doctors (\%) & Female doctors (\%) \\
\hline Semiformal plus smile & 77.4 & 69.4 \\
\hline Semiformal & 49.0 & 40.4 \\
\hline White coat & 36.6 & 31.7 \\
\hline Formal suit & 21.1 & 30.8 \\
\hline Casual & 10.9 & 12.9 \\
\hline Jeans & 10.4 & 9.5 \\
\hline
\end{tabular}




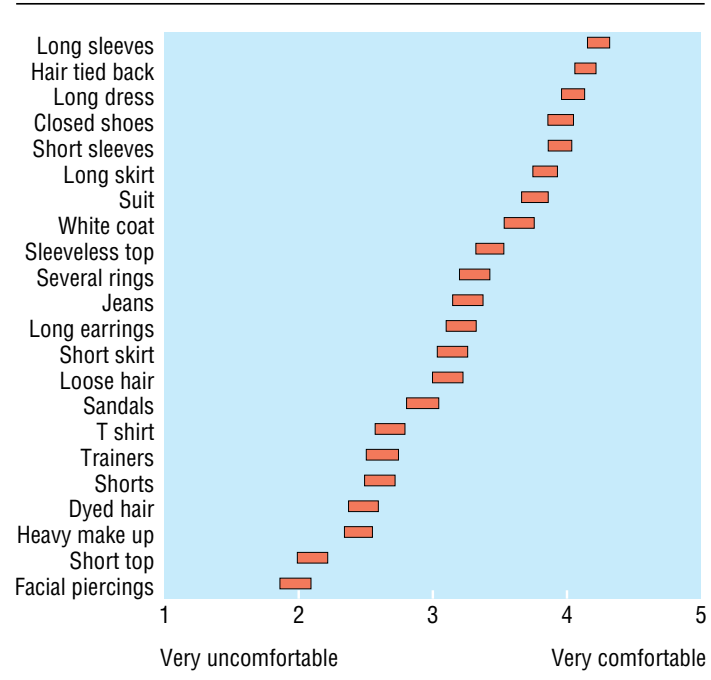

95\% confidence intervals of mean scores

Fig 2 Patients' 95\% Cls of scores for female doctors' items

older patients were (starting with the least acceptable by mean ranking) facial piercings, brightly dyed hair, earrings, $\mathrm{T}$ shirts, training shoes, long hair, several rings, tie depicting a cartoon character, and no tie.

Most patients $(356,79 \%)$ preferred to be called by their first name, with only $20 \%$ preferring title and surname. Participants who preferred to be called by their title and surname were older (mean age 61) than those who preferred to be called by their first name (mean age $54 ; t=3.1, \mathrm{P}<0.01$ ).

Nearly half $(208,46 \%)$ of the patients preferred doctors to introduce themselves by title and first and last name ("Dr Jane Smith"), 27\% (122) by first and last name ("Jane Smith"), 15\% (68) by title and surname ("Dr Smith"), and 10\% (46) by first name only ("Jane"). We found no clear preference according to age $(\mathrm{F}=1.33, \mathrm{df}=3, \mathrm{P}=0.27)$.

Most patients (344, 76\%) stated that doctors should always wear a name badge. The breast pocket was the

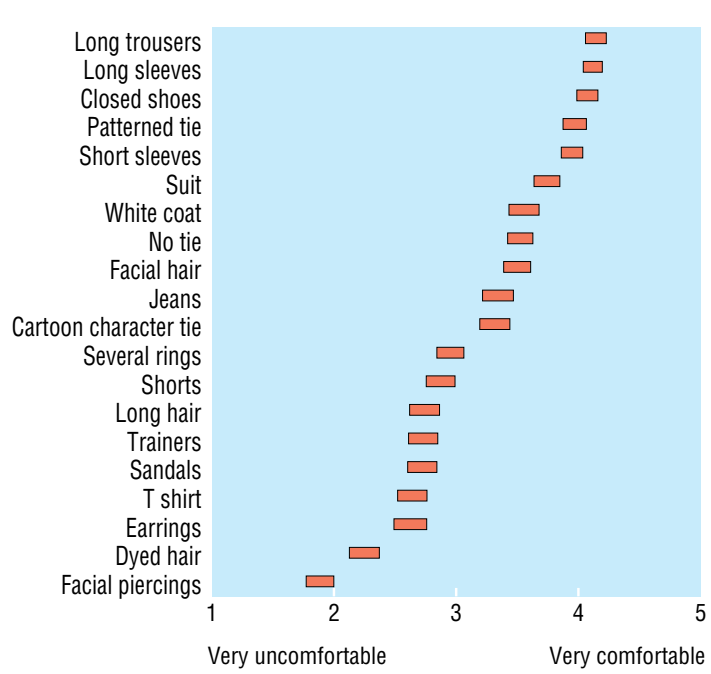

$95 \%$ confidence intervals of mean scores

Fig 3 Patients' $95 \%$ Cls of scores for male doctors' items
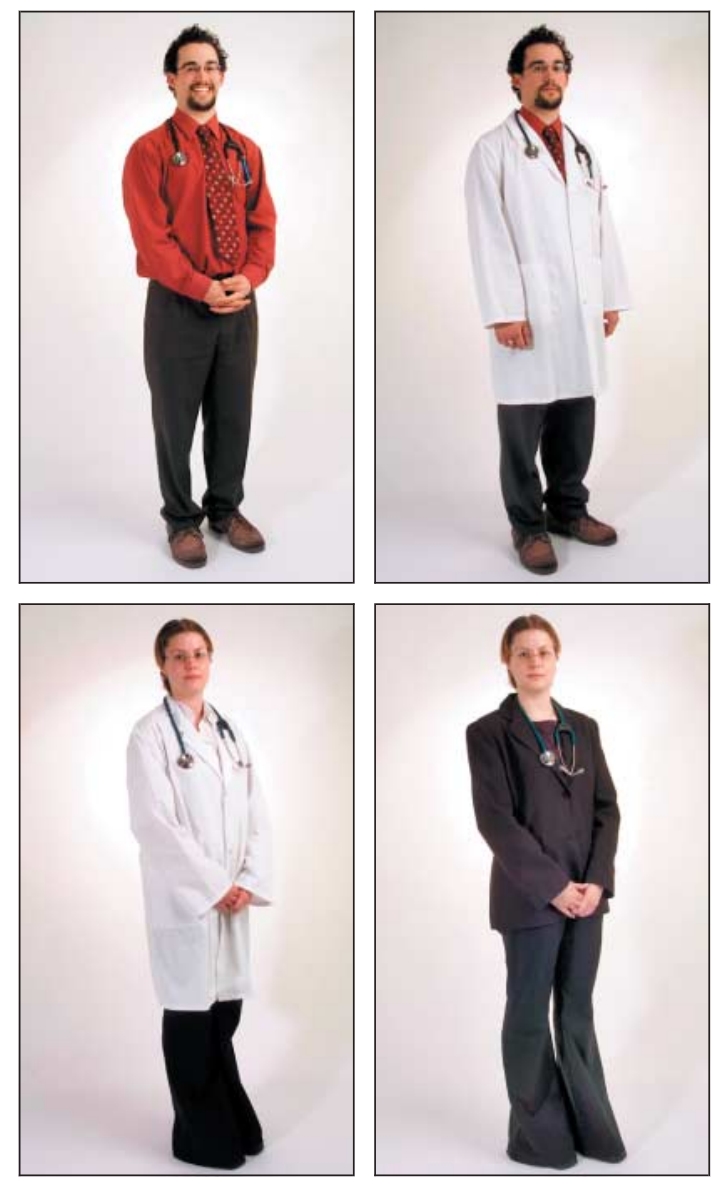

Some sartorial options (see bmj.com for the rest)

preferred site (280, 62\%), with "anywhere as long as they have a name badge" the second most popular $(117,26 \%)$. Only $9.5 \%$ (43) of patients thought that the waist was the best place for a name badge.

\section{Discussion}

Patients prefer doctors to dress in a semiformal style, but when accompanied by a smiling face it is even better, suggesting a friendly manner may be more important than sartorial style.

Although previous studies have shown that patients prefer doctors to wear white coats, we found that patients prefer a semiformal style of dress over formal suits and white coats. In line with previous studies, casual dress styles were less popular. This finding, and the association with age, suggests the beginnings of a trend away from patients preferring white coats. In general, patients prefer more conservative items of clothing.

Most patients prefer their doctor to call them by their first name but prefer doctors to introduce themselves using title and first and last names. Few patients prefer the most casual option of first name only or the most formal option of title and surname. The breast pocket was the most favoured location for a name badge.

The size of our study provided a good cross section of opinions and gave sufficient power to detect small differences in patient preferences. The use of ranking of photographs provided good comparative data and overcame the problem where people may state preferences in theory that are different from preferences in practice. $^{9}$ 
The use of the smiling option in relation only to semiformal dress may have introduced some bias. For example, the higher preferences for the semiformal nonsmiling doctor may have arisen by its association with a smile on another photograph. Ideally each dress style would have been presented with a smiling and non-smiling version, or the smiling option should have been randomly associated with any of the dress styles. Although these results are representative of the patient population at one hospital in New Zealand, we cannot be sure they would be generalisable to other populations.

In view of differences compared with earlier studies, repeating this study at regular intervals to track secular changes would be of value. We predict that the trend will continue for decreasing popularity of white coats. Although sex interactions were not apparent in this study, looking more specifically for this would be worthy of further study. Similarly, qualitative work that explores why patients react in certain ways would be of interest.

Dress style and manner are well within a doctor's control and therefore can be altered to fit most with patient preference. In the New Zealand setting this would involve dressing in a tidy, semiformal manner in conservative clothing. Asking patients if they prefer to be called by their first name may aid comfort. Doctors should introduce themselves fully and clearly, supple- mented by a name badge worn at the breast pocket. A big smile is a definite advantage.

Contributors: Both authors were involved in the design of the study, analysis and interpretation of the results, and in writing the paper. ML undertook the data collection. She is guarantor.

Funding: Summer studentship grant of $\$$ NZ5000 from the Medical Council of New Zealand.

Competing interests: None declared.

Ethical approval: This study was approved by the Canterbury ethics committee.

1 Short D. First impressions. Brit J Hosp Med 1993;50:270-1.

2 Harnett PR. Should doctors wear white coats? Med J Aust 2001;174:343-4. Gooden BR, Smith MJ, Tattersall SJ, Stockler MR. Hospitalised patient' views on doctors and white coats. Med J Aust 2001;175:219-22.

Wong D, Nye K, Hollis P. Microbial flora on doctors' white coats. BMJ 1991;303:1602-4.

5 Gjerdingen DK, Simpson DE, Titus SL. Patients' and physicians' attitudes regarding the physician's professional appearance. Arch Intern Med regarding the physic

6 McKinstry B, WangJX. Putting on the style: what patients think of the way their doctor dresses. Brit J Gen Pract 1991;41:275-8.

Friis R, Tilles J.Patients' preferences for resident physician dress style. Fam Pract Res J 1988;8:24-31.

8 Blondell RD, Humble RS, Roberts DM. How dress affects perceptions of house officers. Am J Dis Child 1987;141:830.

9 Hennessy N, Harrison DA, Aitkenhead AR. The effect of the anaesthetist's attire on patient attitudes. The influence of dress on patient perception of the anaesthetist's prestige Anarsthesia 1993:48:219-29.

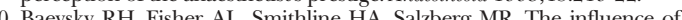
physician attire on patient satisfaction. Acad Emerg Med 1998;5:82-4. (Accepted 30 September 2005)

\section{Patients bearing gifts: are there strings attached?}

\section{Sean A Spence}

The giving of gifts is an ancient and widespread human activity. But when the gift is given by a patient to their doctor then there may be ethical and clinical questions to consider

The love embodied in the gift outlives the giver, affirms his life drive, and adds a sense of beauty to the endurance of life.

It was Christmas Eve and the elderly man had walked in his pyjamas through the sleet and snow, until he reached the accident and emergency department. He already knew that he had cancer, but now he was in acute urinary retention. As luck would have it, the house surgeon who came to see him was the one he knew from the ward; they exchanged banter as the younger man sited a catheter. A few nights later, when the house surgeon was back on the ward, the elderly man called him over. He had a gift for him. It was a bottle of champagne. In his working life he had been the head waiter at a famous restaurant; this champagne was the favourite drink of a celebrity who had dined there. The houseman was speechless with emotion; he liked the man and knew he was about to die. It was the first gift he had received from a patient.

\section{The meaning of gifts}

What does it mean when a patient gives their doctor a gift? Often, it means "thank you for being there," especially at a difficult time. ${ }^{2}{ }^{3}$ The elderly man had walked through the snow, despite being in great pain. Perhaps his gift was offered in thanks for relief from that pain. Perhaps it was an attempt at being understood on another level: as someone who was not always old and ill, but who had worked long hours and earned respect as a head waiter. A single gift may have many "meanings." 45

Although gifts from patients to doctors are common, ${ }^{26}$ they have attracted little systematic research. Most of the available literature comprises case reports and series from the world of psychotherapy ${ }^{157}$; cautionary, anecdotal tales from general practice ${ }^{38}$; and small surveys of hospital doctors. ${ }^{46}$ These data are derived largely from the industrialised West, as reflected in the gifts most often reported: bottles of alcohol and boxes of chocolates. ${ }^{36}$ No one has surveyed the impact of gifts on doctors' health, but their impact on nurses' wellbeing has been investigated. ${ }^{9}$

\section{The giving brain}

What does a gift tell us about the patient's mind and brain? At the very least, in an adult, it indicates that they thought about the doctor before their meeting, during the performance of a purposeful act (the acquisition of a gift). Hence, in the language of psychoanalysis, the gift indicates that the doctor persists in the patient's mind as an internal "object" (that to which action or desire is directed ... that to which the subject relates himself). ${ }^{10}$ Indeed, if the gift is taken at face value, then the doctor constitutes a "good object," one eliciting kindness. Alternatively, from a cognitive neurobiologi-
Academic Clinical Psychiatry, Division of Genomic Medicine, University of S5 7JT

Sean A Spence professor of general adult psychiatry

s.a.spence@ sheffield.ac.uk BMJ 2005;331:1527-9 